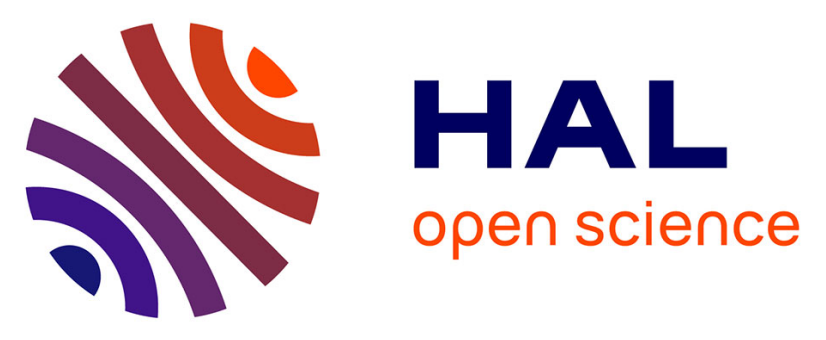

\title{
Development and validation of a questionnaire categorizing behavioral strategies in patients with chronic low back pain
}

Florian Bailly, Violaine Foltz, Sylvie Rozenberg, Michael Norberg, Joelle

Glemarec, Sophie Pouplin, Beatrice Banneville, Christophe Demoulin,

Véronique Gaud-Listrat, Bruno Fautrel, et al.

\section{To cite this version:}

Florian Bailly, Violaine Foltz, Sylvie Rozenberg, Michael Norberg, Joelle Glemarec, et al.. Development and validation of a questionnaire categorizing behavioral strategies in patients with chronic low back pain. Joint Bone Spine, 2017, 10.1016/j.jbspin.2017.02.003 . hal-01480358

\section{HAL Id: hal-01480358 \\ https://hal.sorbonne-universite.fr/hal-01480358}

Submitted on 1 Mar 2017

HAL is a multi-disciplinary open access archive for the deposit and dissemination of scientific research documents, whether they are published or not. The documents may come from teaching and research institutions in France or abroad, or from public or private research centers.
L'archive ouverte pluridisciplinaire HAL, est destinée au dépôt et à la diffusion de documents scientifiques de niveau recherche, publiés ou non, émanant des établissements d'enseignement et de recherche français ou étrangers, des laboratoires publics ou privés. 
Title: Development and validation of a questionnaire categorizing behavioral strategies in patients with chronic low back pain

Author: Florian Bailly Violaine Foltz Sylvie Rozenberg Michael Norberg Joelle Glemarec Sophie Pouplin Beatrice Banneville Christophe Demoulin Véronique Gaud-Listrat Bruno Fautrel Laure Gossec

PII: S1297-319X(17)30014-3

DOI: http://dx.doi.org/doi:10.1016/j.jbspin.2017.02.003

Reference: BONSOI 4541

To appear in:

Accepted date: $\quad$ 21-10-2016

Please cite this article as: Bailly F, Foltz V, Rozenberg S, Norberg M, Glemarec J, Pouplin S, Banneville B, Demoulin C, Gaud-Listrat V, Fautrel B, Gossec L, Development and validation of a questionnaire categorizing behavioral strategies in patients with chronic low back pain, Joint Bone Spine (2017), http://dx.doi.org/10.1016/j.jbspin.2017.02.003

This is a PDF file of an unedited manuscript that has been accepted for publication. As a service to our customers we are providing this early version of the manuscript. The manuscript will undergo copyediting, typesetting, and review of the resulting proof before it is published in its final form. Please note that during the production process errors may be discovered which could affect the content, and all legal disclaimers that apply to the journal pertain. 
Development and validation of a questionnaire categorizing behavioral strategies in patients with chronic low back pain

Florian Bailly; ${ }^{1,2}$ Violaine Foltz; ${ }^{1,2}$ Sylvie Rozenberg; ${ }^{1,2}$ Michael Norberg; ${ }^{3}$ Joelle

Glemarec; ${ }^{4}$ Sophie Pouplin; ${ }^{5}$ Beatrice Banneville; ${ }^{1}$ Christophe Demoulin; ${ }^{7}$ Véronique GaudListrat ${ }^{8}$ Bruno Fautrel; ${ }^{1,2}$ Laure Gossec ${ }^{1,2}$

1 - Service de Rhumatologie, Hôpital Pitié Salpêtrière, AP-HP, 75013 Paris, France

2 - Institut Pierre Louis d'Epidémiologie et de Santé Publique, Sorbonne Universités, UPMC Univ Paris 06, Paris 75013, France

3 - Service MPR, Centre hospitalier universitaire vaudois, 1011 Lausanne, Switzerland 4 - Centre hospitalier de Nantes, 44093 Nantes, France

5 - Centre hospitalier Charles Nicolle, 76000 Rouen, France

6 - Département des Sciences de la Motricité, Université de Liège, 4000 Liège, Belgium 7 - Service de 1'Appareil Locomoteur, CHU de Liège, 4000 Liège, Belgium

8 - AP-HP, Hopital Cochin, Service de Rhumatologie B, 75014 Paris, France

\section{Corresponding author:}

Florian Bailly,

Service de Rhumatologie, Hôpital Pitié-Salpêtrière, 47-83, boulevard de l'Hôpital - 75013

Paris France

E-mail: florian.bailly@aphp.fr

Tel.: +33142177821 


\begin{abstract}
Objective: The identification of helpful or unhelpful behavioral strategies for coping with pain would assist in optimizing the management of patients with chronic low back pain (CLBP).
\end{abstract}

To develop and validate a questionnaire for categorizing behavioral strategies in patients with nonspecific CLBP.

Methods: (1) Development of a preliminary questionnaire based on a qualitative study in 25 patients with CLBP; (2) Item reduction and questionnaire validation by a multicenter international prospective study in patients with CLBP, with multiple correspondence analysis to identify behavioral profiles, whose characteristics and internal and external validities were assessed; 12-month study of treatments in 58 patients; (3) Evaluation of reproducibility in 30 patients.

Results: (1) The preliminary questionnaire had 87 items in eight pain-coping domains. (2) Three behavioral profiles were identified: effective coping, emotional distress, and kinesiophobia. The questionnaire was reduced to 21 items in seven domains. Cronbach's $\alpha$ indicated moderate internal consistency (0.47-0.66). External validity versus anxiety, depression, and coping strategies was good. As expected, exercise reconditioning was used more often by patients with kinesiophobia than by those with effective coping ( $50 \% \mathrm{vs}$. $25 \%, P<0.05)$. (3) Reproducibility was good $(\kappa=0.70)$.

Conclusion: This new, simple questionnaire allows the identification of three behavioral profiles, thus guiding the development of personalized management programs for NCLBP.

Keywords: Low back pain. Questionnaire. Coping. Behavior. Management. Pain management. Adjustment strategy. 


\section{Introduction}

Nonspecific chronic low back pain (NCLBP) is a common condition whose worldwide prevalence of $9.7 \%$ remained unchanged between 1990 and 2010 [1]. NCLBP is a major source of functional impairment. Thus, according to the worldwide epidemiological Global Burden of Disease study, NCLBP is the leading cause of years lived with disability [1]. Nevertheless, some progress has been achieved. The World Health Organization has moved away from the early anatomical-clinical model, in which the pain was ascribed to a spinal lesion, toward a biopsychosocial model that attributes the pain to complex interactions among anatomical, psychological, social, and occupational factors [2]. By emphasizing differences across patients, this model highlights the need for a personalized and multimodal management strategy that focuses on the full range of patient characteristics instead of merely on the topographic distribution of the pain.

Among the many treatments proven effective in NCLBP, physical therapy, educational interventions, multidisciplinary management, and cognitive-behavioral therapy are recommended in European guidelines [3]. Nevertheless, selecting the best treatment program for each individual patient is challenging in clinical practice. The recommendations encourage the identification of patient subgroups and the use of treatment strategies targeted to specific patient profiles. The STarT Back Screening Tool (SBST) is a questionnaire for categorizing the risk of progression to chronic pain and disability. In a randomized trial, management stratified on the SBST risk profile (physiotherapy, psychological support, social support) was significantly more effective than standard care [4]. However, SBST results are interpreted by the physician and not directly by the patient. The SBST-based 
model does not involve advice to the patient about pain management and, consequently, fails to contribute to patient education.

As demonstrated in several studies, pain coping strategies vary across patients and exert a major influence on the impact of pain $[5,6]$. These differences should be taken into consideration when selecting the treatment strategy for a patient with NCLBP [7].

Evaluating pain-coping strategies may serve both the physician and the patient in several ways [8]: once identified, inadequate or suboptimal pain-coping strategies become treatment targets for the physician; and the patient may discover alternative strategies for managing everyday activities, participate actively in the treatment strategy, and define his or her own objectives (shared objectives for therapeutic patient education).

To date, no easy-to-use tool for assessing behavioral strategies developed by patients with NCLBP for coping with pain and disability is available. Such a tool would provide guidance to patients for managing their pain and to physicians for selecting the best treatment approach.

Here, our objective was to develop and validate a self-administered questionnaire suitable for use in everyday practice and capable of identifying behavioral pain-coping profiles of patients with NCLBP.

\section{Methods}

The Back Pain Behavioral Profile (BP2) was developed from 2012 to 2015 under the coordination of a rheumatology research group at the Pitié-Salpêtrière Teaching Hospital in Paris (France) and by the Spine Section of the French Society for Rheumatology (SFR). The OMERACT filter was applied to patient-reported outcomes $[9,10]$. A preliminary 
questionnaire developed based on the verbatim patient reports was evaluated prospectively then modified to obtain the final questionnaire, whose reproducibility was assessed (Figure $1)$.

\section{1/ Development of the preliminary questionnaire}

A qualitative study was conducted in 25 patients with NCLBP [11], who participated in semi-structured focus groups. The results were used by five rheumatologists to develop a preliminary questionnaire. Pain management strategies were identified in eight domains of everyday life: pain, daily activities, physical and recreational activities, emotions and morale, reactions of others, occupational activities, future, and drug treatments. For each of these domains, a question was developed. Multiple-choice response options were created based on the verbatim patient reports. All items were framed using similar syntax, without negations [10]. Numerous items were selected, without considering potential redundancies, to cover the full range of statements made during the focus groups. The verbatim focusgroup transcripts were read again to check their consistency with the questionnaire items. The preliminary questionnaire was evaluated by both one-on-one cognitive interviewing of 5 patients [12,13] and overall Internet-based assessments by 8 focus-group patients and 3 of the experts in charge of patient recruitment. The following were evaluated: comprehension of the question (Does the patient understand the question?), information retrieval (Is the patient able to recall the required information?), and judgment (Is the patient able to make a judgment?). If indicated by the responses of the participants, the questions were reworded and the items reworded or deleted. 


\section{2/ Development of the final questionnaire}

We conducted a prospective multicenter observational 12-month study between 2012 and 2015 in patients seeking medical advice for NCLBP. Each patient completed the abovedescribed preliminary questionnaire and several validated questionnaires with the goal of defining and validating behavioral profiles and of selecting the items for the final questionnaire. The study was approved by the appropriate ethics committee (CPP Ile de France VI) on October 24, 2012, and reported to the Advisory Committee on Data Processing in Healthcare Research (CCTIRS, \#12.492) and French Data Protection Authority (CNIL, \#1632885).

\section{Inclusion criteria}

Inclusion criteria were as follows: (a) NCLBP of at least 6 weeks' duration, with or without distal radiation, with no indication for surgery; (b) NCLBP as the main reason for seeking medical advice; (c) age older than 18 years; (d) informed consent provided; (e) fluency in spoken and written French; (f) no spinal surgery within the past 3 months; (g) and visual analog scale (VAS) for low back pain greater than 4/10.Members of the Spine Section of the French Society for Rheumatology (SFR) recruited nonconsecutive patients at specialized centers in Belgium, France, and Switzerland.

\section{Source and nature of collected data}

The inclusion criteria were checked and written informed consent obtained during a physician visit. Each study patient completed a case-report form via a secure Internet site; patients without Internet access were mailed the printed questionnaire at home.

The following data were collected at inclusion: sociodemographic data (age, gender, educational background, and job category as classified by the French National Institute of Statistics and Economic Studies (INSEE); characteristics of the low back pain (duration, 
intensity on a VAS, and presence or absence of distal radiation);preliminary questionnaire; validated French versions of the following questionnaires: Patient Acceptable Symptom State (PASS) [14], Rolland Morris Questionnaire [15], Fear Avoidance Belief Questionnaire (FABQ) [16], Coping Strategies Questionnaire (CSQ) [17], and Hospital Anxiety and Depression Scale (HADS) [18]; we used the following validated cut-offs: HADS, $\geq 8 / 21$ for the anxiety and depression subscores; and FABQ $\geq 15 / 24$ and $\geq 30 / 42$ for the physical activity and work subscores, respectively $[19,20]$.

Our working hypotheses were that patients would cluster into different behavioral profiles based on characteristics such as anxiety, depression, false beliefs, and coping methods and that the treatments used during follow-up would differ across these groups. Patient management was at the discretion of the physicians, who were unaware of the questionnaire results. Those patients who had participated via the Internet site were contacted 12 months after the initial data collection and asked which treatments they had used (physical therapy, exercise reconditioning, antidepressants, therapy with a psychologist or psychiatrist, and/or spinal surgery).

\section{3/ Evaluation of the reproducibility of the final questionnaire}

The final questionnaire was completed by 30 patients who had not participated in the previous steps of the study. Inclusion criteria were as follows: age older than 18 years, fluency in spoken and written French, NCLBP of at least 6 weeks' duration, and naïve to therapeutic patient education and exercise reconditioning. Each patient completed the questionnaire twice at an interval of 2 to 7 days. 
Questionnaire scoring, interpretation, and translation into therapeutic advice

A total score was to be defined, with attention to achieving optimal discrimination. For each behavioral cluster, an interpretation and therapeutic advice were developed by a group of experts, a therapeutic-patient-education nurse, and a physical therapist. Finally, 5 patients underwent cognitive interviewing to assess comprehension of the questionnaire $[12,13]$.

\section{Statistical analysis}

Multiple correspondence analysis [21] followed by hierarchical cluster analysis were applied to the preliminary questionnaire items to identify behavioral clusters. Internal validity of the results was assessed by computing Cronbach's $\alpha$ [23] and external validity by comparison with the results of the other questionnaires. Longitudinal validity was evaluated also. For each question, the item with the best discrimination in each cluster was selected by the panel of experts based on the statistical results. Questions that diminished the ability of the questionnaire to discriminate among clusters (as shown by a lower Cronbach's $\alpha$ value) were to be deleted. In the final questionnaire, each question was to have a single item for each behavioral cluster. The Type I error was set at 5\%. Reproducibility of the questionnaire was assessed by computing Cohen's $\kappa$ [24]. R software version 3.0.1 was used for the statistical analysis.

\section{Role of the funding source}

This study was funded by grant \#2350 from the French Society of Rheumatology (SFR).

\section{Results}




\section{1/ Development of the preliminary questionnaire}

Based on the data from the four focus groups and on the eight predefined painmanagement domains, 89 items relevant to pain-management strategies were identified. The items were assigned to the relevant pain-management domain and multiple-choice response options were developed for each. Comprehension and ease of recall were then evaluated. The results prompted rewording of several items and deletion of two items. This left 87 items for the eight questions.

\section{2/ Development of the final questionnaire}

We included 118 patients, among whom $60 \%$ were females. Mean age was 50 years. Most of the patients had had NCLBP for several years (Table 1). By multiple correspondence analysis, a three-cluster solution was optimal. Hierarchical cluster analysis was used to distribute the patients among these three clusters. The clinical significance of the statistically identified cluster was evaluated by analyzing the items most closely associated with each cluster (Table 2).

The three clusters were as follows: effective coping strategy, without false beliefs, kinesiophobia, or marked depressive affect; emotional distress, with prominent manifestations of anxiety, depression, and/or catastrophizing, clouding the view of the future; and kinesiophobia (in the absence of a formal assessment of this manifestation) with fear of moving and irrational beliefs leading to a marked decrease in motor activity. For each of these three groups and each question, the experts selected the most appropriate item for the final questionnaire. The question on managing medications diminished the internal consistency of the questionnaire and was consequently deleted. Cronbach's $\alpha$ values for the 
effective-coping, emotional-distress, and kinesiophobia groups were $0.64,0.46$, and 0.57 , respectively.

As few patients had emotional distress, external validity was difficult to assess in this cluster. The effective-coping cluster had more patients in the patient-acceptable symptom state (PASS question) and fewer patients with anxiety and/or depression (HADS) and/or false beliefs (FABQ), compared to the patients with kinesiophobia. Similarly, according to the CSQ, the positive strategy consisting in ignoring the pain sensations was more common in the effective-coping cluster, whereas the negative strategy consisting in catastrophizing was more common in the kinesiophobia and emotional-distress clusters (Table 3).

Of the 84 patients contacted after 12 months, 58 responded; the response rates were $59 \%$ in the effective-coping cluster and $41 \%$ in the kinesiophobia cluster . Exercise reconditioning was used by a significantly larger proportion of patients in the kinesiophobia cluster compared to the effective-coping cluster ( $50 \%$ vs. $24 \%, P<0.05$ ). No significant differences were found across clusters in the use of other treatment modalities (physical therapy, surgery, antidepressants, therapy with a psychologist or psychiatrist).

\section{3/ Evaluation of the reproducibility of the final questionnaire}

Test-retest reliability was assessed by having 30 patients complete the final questionnaire twice, at a median interval of 5 days. Among these patients, $70 \%, 13 \%$, and $17 \%$ were in the effective-coping, emotional-distress, and kinesiophobia clusters, respectively. Cohen's $\kappa$ was 0.70 , indicating satisfactory reproducibility of patient classification within behavioral groups.

A simple scoring system was devised: the number of items in each behavioral cluster was determined, without weighting, and the cluster with the largest number of items was taken as 
describing the patient's profile. When two clusters had the same number of items, the patient was asked to choose the item he/she felt was the most important, and that item determined the predominant behavioral profile. Interpretations of the questionnaire results and their translations into clinical advice were developed by the study experts then evaluated by cognitive interviewing of 5 patients. Several sentences were reworded. The patients felt that the scoring system was easy to understand and to use. The final questionnaire thus obtained is provided in Figure 2 and Appendix A, Text S1 [See the supplementary material associated with this article online].

\section{Discussion}

This study defined three behavioral pain-management profiles in patients with NCLBP: kinesiophobia requiring reassurance about physical capabilities, emotional distress requiring psychological support, and effective coping. The number of patients was largest in the effective-coping cluster and smallest in the emotional-distress cluster. The BP2 questionnaire readily and rapidly identifies the patient's behavioral profile, thereby providing therapeutic guidance. In addition, the common-sense advice to patients developed for each profile enhances the benefits of the BP2 questionnaire. Patients with effective coping are advised to follow the standard strategy combining information, analgesics, and physical therapy. Combined psychological and physical treatments are recommended for patients with emotional distress. Finally, patients with kinesiophobia are guided toward intensive multidisciplinary physical treatments such as exercise reconditioning. These 
suggestions are consistent with the treatments followed by the patients in our three groups but need to be validated in an independent study.

The identification in our study of different behaviors requiring different types of advice and management is consistent with earlier reports. In a large, prospective, populationbased cohort, catastrophizing and kinesiophobia independently predicted chronic low back pain, even in individuals without low back pain at baseline [25]. Catastrophizing was a component of our emotional distress profile, and kinesiophobia characterized the other unhelpful behavior, although specific questionnaires for catastrophizing and kinesiophobia were not used. During 12 months of treatment by the usual physicians, exercise reconditioning was more often used in the kinesiophobia cluster, supporting the validity of our cluster solution. Nevertheless, we did not assess whether the patient's opinion matched the cluster assigned by the questionnaire. Previous studies also identified various painmanagement strategies in patients with NCLBP. One group identified three clusters based on pain intensity, disability, depression, and coping strategies: chronic pain syndrome, positive adaptation to pain, and good pain control [26,27]. This group used a cluster analysis approach similar to ours and identified similar clusters of characteristics but did not allow the development of a questionnaire suitable for use in everyday practice.

The small number of patients in the emotional-distress cluster is consistent with the small proportion of patients with major depression. Although expected, this small number limits the interpretations that can be made for the emotional-distress cluster. Nevertheless, patients with emotional distress should be identified, since they can be offered specific treatments and are at high risk for chronic pain [28]. The change in the proportion of patients with emotional distress between our two study time points (3\% vs. $13 \%)$ reflects the variability of psychological well-being. A study in a different population is needed to 
validate the three clusters and the distribution of patients among them. This future study should also validate some of the cluster characteristics, such as kinesiophobia, which was not included in the initial analysis.

The recently developed SBST classifies patients into three groups based on the risk of chronic pain (low, moderate, and high). This very simple 9-item questionnaire has been validated and proven effective for stratifying the primary-care management of patients with low back pain [4]. Nevertheless, identifying patients at high risk for chronic pain is not relevant in patients who already have chronic low back pain. In addition, the SBST is designed to help physicians stratify patient management and does not directly provide guidance to the patients.

The patients included in the development and validation cohort had had NCLBP for several years. This high level of chronicity may limit the external validity of our study. Nevertheless, the large sample size, multicenter recruitment, and small proportion of patients treated with exercise reconditioning are representative of patients seeking further options after failure of the initial treatment of low back pain. A study validating the BP2 questionnaire in patients with subacute low back pain may prove of interest.

The development and validation of self-administered questionnaires is a vast field of research that has received considerable attention from the rheumatology community, given the largely subjective nature of musculoskeletal symptoms [29-35]. The methodology used for our study, notably the initial qualitative phase and the reliance on expert opinion, may have induced some measure of subjectivity. When developing the questionnaire, we applied validated methods based on patient-derived data and expert opinion [29,30,34,35]. A limitation of using verbatim patient reports for developing the questionnaire is that patients fail to report some types of information, such as a desire for secondary gains. Validation of 
the questionnaire also relied on established methods [9,36,37]. Our choice of multiple correspondence analysis allowed us to identify objective clusters that were validated statistically, without making subjective choices. Nevertheless, future studies should validate our clusters, notably the emotion-distress cluster, given its very small number of patients.

In sum, the questionnaire developed in this study should prove useful to both patients and physicians. Patients obtain information about the appropriateness of their behavior and advice on how to improve their pain-management strategy. Physicians may find the questionnaire useful for adjusting the treatment approach, suggesting a type of therapeutic patient education, or recommending a specific treatment modality such as exercise reconditioning. The questionnaire may prove particularly helpful to physicians who are not specialized in spinal diseases and may therefore be unsure about the best treatment program. Wide dissemination of the questionnaire among patients seeking to improve their behavior may provide benefits. These possibilities deserve evaluation in a longitudinal study.

Disclosure of interest: None of the authors has any conflicts of interest to declare. Acknowledgments: We are grateful to the French Society for Rheumatology (SFR) for providing the grant that funded this study. We thank the Spine Section of the SFR and the physicians who recruited the patients: Dr Dupeyron, Dr Genevay, and Dr Maigne.

\section{Appendix A. Supplementary data}

Supplementary data (Text S1) associated with this article can be found in the online version at ... 


\section{References}

[1] Vos T, Flaxman AD, Naghavi M. Years lived with disability (YLDs) for 1160 sequelae of 289 diseases and injuries 1990-2010: a systematic analysis for the Global Burden of Disease Study 2010. Lancet 2012;380:2163-96.

[2] World Health Organization. classification internationale des handicaps: déficiences, incapacités et désavantages, un manuel de classification des conséquences des maladies. 1980,204 p.

[3] Airaksinen O, Brox JI, Cedraschi C, et al. Chapter 4 European guidelines for the management of chronic nonspecific low back pain. Eur Spine J 2006;15:192-300. [4] Hill JC, Whitehurst DG, Lewis M, et al. Comparison of stratified primary care management for low back pain with current best practice (STarT Back): a randomised controlled trial. Lancet 2011;378:1560-71.

[5] Snelgrove S, Liossi C. Living with chronic low back pain: a metasynthesis of qualitative research. Chronic Illn 2013;9:283-301.

[6] Snelgrove S, Edwards S, Liossi C. A longitudinal study of patients' experiences of chronic low back pain using interpretative phenomenological analysis: changes and consistencies. Psychol Health 2013;28:121-38.

[7] Rozenberg S, Foltz V, Fautrel B. Stratégie thérapeutique devant une lombalgie chronique. Rev Rhum 2012;79:A27-31.Treatment strategy for chronic low back pain. Joint Bone Spine. 2012;79:555-9

[8] Kirwan J, Heiberg T, Hewlett S, et al. Outcomes from the Patient Perspective Workshop at OMERACT 6. J Rheumatol. 2003;30:868-72.

[9] Boers M, Brooks P, Strand C V, Tugwell P. The OMERACT filter for Outcome Measures in Rheumatology. J Rheumatol 1998;25:198-9. 
[10] Kirwan JR, Bartlett SJ, Beaton DE, et al. Updating the OMERACT filter: implications for patient-reported outcomes. J Rheumatol 2014;41:1011-5.

[11] Bailly F, Foltz V, Rozenberg S, Fautrel B, Gossec L. The impact of chronic low back pain is partly related to loss of social role: A qualitative study. Joint Bone Spine. $2015 ; 82:: 437-41$.

[12] Drennan J. Cognitive interviewing: verbal data in the design and pretesting of questionnaires. 2003:57-63.

[13] Pincus T, Santos R, Breen A, Burton AK, Underwood M. A review and proposal for a core set of factors for prospective cohorts in low back pain: a consensus statement. Arthritis Rheum 2008;59:14-24.

[14] Pham T, Tubach F. Patient acceptable symptomatic state (PASS). Joint Bone Spine 2009;76:321-3.

[15] Coste J, Parc JM Le, Berge E, Delecoeuillerie G, Paolaggi JB. [French validation of a disability rating scale for the evaluation of low back pain (EIFEL questionnaire)]. Rev Rhum Ed Fr 1993;60:335-41.

[16] Chaory K, Fayad F, Rannou F, et al. Validation of the French version of the fear avoidance belief questionnaire. Spine (Phila Pa 1976) 2004;29:908-13.

[17] Irachabal S, Koleck M, Rascle N, Bruchon-Schweitzer M. [Pain coping strategies: French adaptation of the coping strategies questionnaire (CSQ-F)]. Encephale 2008;34:4753. [18] Lépine JP, Godchau M, Brun P, Lempérière T. [Evaluation of anxiety and depression among patients hospitalized on an internal medicine service]. Ann médico-psychologiques $1985 ; 143: 175-89$.

[19] Burton AK, Waddell G, Tillotson KM, Summerton N. Information and advice to 
patients with back pain can have a positive effect a randomized controlled trial of a novel educational booklet in primary care. 1999;24:2484-91.

[20] Bjelland I, Dahl A a, Haug TT, Neckelmann D. The validity of the Hospital Anxiety and Depression Scale. An updated literature review. J Psychosom Res 2002;52:69-77. [21] Everitt BS, Howell DC eds. Encyclopedia of Statistics in Behavioral Science. Chichester, UK: John Wiley \& Sons, Ltd; 2005.

[22] Johnson SC. Hierarchical clustering schemes. Psychometrika 1967;32:241-54.

[23] Cronbach LJ. Coefficient alpha and the internal structure of tests. Psychometrika $1951 ; 16: 297-334$.

[24] Cohen J. A coefficient of agreement for nominal scales. Educ Psychol Meas $1960 ; 202: 27-46$.

[25] Picavet HS, Vlaeyen JW, Schouten JS. Pain catastrophizing and kinesiophobia: Predictors of chronic low back pain. Am J Epidemiol 2002;156:1028-34.

[26] Klapow JC, Slater MA, Patterson TL, Doctor JN, Atkinson JH, Garfin SR. An empirical evaluation of multidimensional clinical outcome in chronic low back pain patients. Pain 1993;55:107-18.

[27] Klapow JC, Slater MA, Patterson TL, et al. Psychosocial factors discriminate multidimensional clinical groups of chronic low back pain patients. Pain 1995;62:349-55. [28] Fransen M, Woodward M, Norton R, Coggan C, Dawe M, Sheridan N. Risk factors associated with the transition from acute to chronic occupational back pain. Spine (Phila Pa 1976) $2002 ; 27: 92-8$.

[29] Gossec L, Dougados M, Rincheval N, et al. Elaboration of the preliminary Rheumatoid Arthritis Impact of Disease (RAID) score: a EULAR initiative. Ann Rheum Dis 2009;68:1680-5. 
[30] Gossec L, Wit M de, Kiltz U, et al. A patient-derived and patient-reported outcome measure for assessing psoriatic arthritis: elaboration and preliminary validation of the Psoriatic Arthritis Impact of Disease (PsAID) questionnaire, a 13-country EULAR initiative. Ann Rheum Dis 2014;73:1012-9.

[31] Pincus T, Swearingen CJ, Bergman M, Yazici Y. RAPID3 (Routine Assessment of Patient Index Data 3), a rheumatoid arthritis index without formal joint counts for routine care: proposed severity categories compared to Disease Activity Score and Clinical Disease Activity Index Categories. J Rheumatol 2008;35:2136-47.

[32] Fries JF, Spitz PW, Young DY. The dimensions of health outcomes: the health assessment questionnaire, disability and pain scales. J Rheumatol 1982;9:789-93. [33] Castrejón I, Gossec L, Carmona L. The EULAR Outcome Measures Library: an evolutional database of validated patient-reported instruments. Ann Rheum Dis $2015 ; 74: 475-6$.

[34] Hewlett S, Dures E, Almeida C. Measures of fatigue: Bristol Rheumatoid Arthritis Fatigue Multi-Dimensional Questionnaire (BRAF MDQ), Bristol Rheumatoid Arthritis Fatigue Numerical Rating Scales (BRAF NRS) for severity, effect, and coping, Chalder Fatigue Questionnaire (CFQ), Checklist. Arthritis Care Res (Hoboken) 2011;63 Suppl $1:$ S263-86.

[35] Sanderson T, Morris M, Calnan M, Richards P, Hewlett S. Patient perspective of measuring treatment efficacy: the rheumatoid arthritis patient priorities for pharmacologic interventions outcomes. Arthritis Care Res (Hoboken) 2010;62:647-56.

[36] Boers M, Kirwan JR, Wells G, et al. Developing core outcome measurement sets for clinical trials: OMERACT filter 2.0. J Clin Epidemiol 2014;67:745-53.

[37] Mokkink LB, Terwee CB, Patrick DL, et al. The COSMIN checklist for assessing the 
methodological quality of studies on measurement properties of health status measurement instruments: an international Delphi study. Qual Life Res 2010;19:539-49. 
Table 1: Clinical features of the patients included in the prospective multicenter study designed to develop the questionnaire

\begin{tabular}{|c|c|c|c|}
\hline & $\begin{array}{l}\text { Population in the } \\
\text { prospective } \\
\text { multicenter study } \\
(\mathrm{n}=118)\end{array}$ & $\begin{array}{l}\text { Prospective } \\
\text { multicenter } \\
\text { study subgroup } \\
\text { with follow-up } \\
\text { data } \\
(n=58)\end{array}$ & $\begin{array}{l}\text { Test-retest } \\
\text { population } \\
(n=30)\end{array}$ \\
\hline Age, years, median (range) & $51(22-77)$ & $49(22-77)$ & $50(23-78)$ \\
\hline Females, N (\%) & $71(60)$ & $31(53)$ & $18(60)$ \\
\hline $\begin{array}{l}\text { Duration of NCLBP, years, } \\
\text { median (range) }\end{array}$ & $8,0(0,3-56)$ & $8,0(0,5-40)$ & $2,0(0,2-20)$ \\
\hline $\begin{array}{l}\text { Radiation to a lower limb, N } \\
\text { (\%) }\end{array}$ & $88(75)$ & $45(77)$ & $17(57)$ \\
\hline $\begin{array}{l}\text { VAS for low back pain/10, } \\
\text { median (range) }\end{array}$ & $6,0(4-10)$ & $4,8(1-9)$ & $5,6(3-9)$ \\
\hline $\begin{array}{l}\text { Participation in exercise } \\
\text { reconditioning/back school, } \mathrm{N} \\
(\%)\end{array}$ & $44(37)$ & $26(45)$ & $0(0)$ \\
\hline Sick leave, N (\%) & $32 / 105(30)$ & $12 / 51(24)$ & $7 / 26(27)$ \\
\hline
\end{tabular}

NCLBP, nonspecific chronic low back pain; VAS, visual analog scale 
Table 2: Items most strongly associated with the behavioral clusters

\begin{tabular}{|c|c|c|}
\hline & $\begin{array}{l}\% \text { of patients } \\
\text { in the cluster } \\
\text { who selected } \\
\text { the item }\end{array}$ & $\begin{array}{l}\% \text { of patients in } \\
\text { other clusters } \\
\text { who selected } \\
\text { the item }\end{array}$ \\
\hline \multicolumn{3}{|c|}{ Effective-coping cluster ( $60 \%$ of the initial population) } \\
\hline $\begin{array}{l}\text { I have learned to deal with my pain while going } \\
\text { about my usual activities. }\end{array}$ & $67 \%$ & $32 \%$ \\
\hline $\begin{array}{l}\text { I accept the future, although I know the pain may } \\
\text { still be there. }\end{array}$ & $70 \%$ & $25 \%$ \\
\hline \multicolumn{3}{|c|}{ Emotional-distress cluster (3\% of the initial population) } \\
\hline I feel l'm a burden for others. & $100 \%$ & $13 \%$ \\
\hline I feel my pain is dragging me down & $100 \%$ & $16 \%$ \\
\hline \multicolumn{3}{|l|}{ Kinesiophobia group ( $37 \%$ of the initial population) } \\
\hline I am fearful about the future. & $59 \%$ & $10 \%$ \\
\hline I no longer carry out my usual activities & $50 \%$ & $17 \%$ \\
\hline
\end{tabular}


Table 3: External validity of the three behavioral clusters identified by the questionnaire

\begin{tabular}{|c|c|c|c|c|}
\hline Variables & $\begin{array}{l}\text { Effective } \\
\text { coping }(n=71)\end{array}$ & $\begin{array}{l}\text { Emotional } \\
\text { distress ( } \mathrm{n} \\
=3 \text { ) }\end{array}$ & $\begin{array}{l}\text { Kinesiophobia } \\
(N=44)\end{array}$ & $P$ value \\
\hline Initial VAS pain score /10 & $6.2(1.4)$ & $4.3(0.6)$ & $6.3(1.6)$ & 0.092 \\
\hline Sick leave & $27 \%(45)$ & $33 \%(58)$ & $34 \%(48)$ & 0.79 \\
\hline PASS & $35 \%(48)$ & $33 \%(58)$ & $7 \%(25)^{*}$ & $0.003^{\varepsilon}$ \\
\hline HADS anxiety cutoff $\geq 8 / 21$ & $42 \%(50)$ & $\begin{array}{l}100 \% \\
(0)\end{array}$ & $91 \%(29)$ & $<0.001^{£}$ \\
\hline $\begin{array}{l}\text { HADS depression cutoff } \geq \\
8 / 21\end{array}$ & $15 \%(36)$ & $100 \%(0)$ & $65 \%(48)$ & $<0.001^{\varepsilon}$ \\
\hline $\begin{array}{l}\text { FABQ Physical activities } \geq \\
15 / 24\end{array}$ & $41 \%(50)$ & $33 \%(58)$ & $65 \%(48)^{\star *}$ & $0.037^{£}$ \\
\hline FABQ Work $\geq 30 / 42$ & $18 \%(39)$ & $0 \%(0)$ & $38 \%(49)^{\star \star}$ & $0.048^{\varepsilon}$ \\
\hline $\begin{array}{l}\text { EIFEL (Rolland Morris) at } \\
\text { baseline / } 24\end{array}$ & $6.9(3.7)$ & $12.7(2.3)$ & $12.3(3.4)$ & 0.304 \\
\hline $\begin{array}{l}\text { CSQ Positive Ignoring pain } \\
\text { sensations /16 }\end{array}$ & $11.4 \quad(3.5)$ & $14.3(3.1)$ & $9.1(2.2)^{* * *}$ & $0.001^{£}$ \\
\hline $\begin{array}{l}\text { CSQ Negative Distraction / } \\
20\end{array}$ & $10.7(3.7)$ & $12.0(3.6)$ & $10.6(3.2)$ & 0.761 \\
\hline $\begin{array}{l}\text { CSQ Negative } \\
\text { Catastrophizing }\end{array}$ & $8.1(2.6)$ & $10.3(1.2)$ & $11.4(2.5)^{* * *}$ & $<0.001^{\varepsilon}$ \\
\hline $\begin{array}{l}\text { CSQ Positive Reinterpreting } \\
\text { /16 }\end{array}$ & $6.3(2.6)$ & $4.7(1.2)$ & $5.5(1.8)$ & 0.344 \\
\hline CSQ Negative Praying / 12 & $5.0(2.7)$ & $6.3(4.2)$ & $5.9(2.6)$ & 0.080 \\
\hline
\end{tabular}

VAS, visual analog scale; PASS, patient-acceptable symptom state; HADS, Hospital Anxiety and Depression Scale; FABQ, Fear Avoidance and Beliefs Questionnaire; EIFEL, validated French version of the Rolland Morris questionnaire; CSQ, Coping Strategies Questionnaire 
The data are mean \pm SD or $\mathrm{n}(\%)$.

The asterisks mark significant $P$ values (Kruskal-Wallis test): $* P<0.01, * * P<0.05$, and $* * * P<0.001$ 
Figure 1 : is the study flowchart

Figure 2 : Questionnaire on managing low back pain 


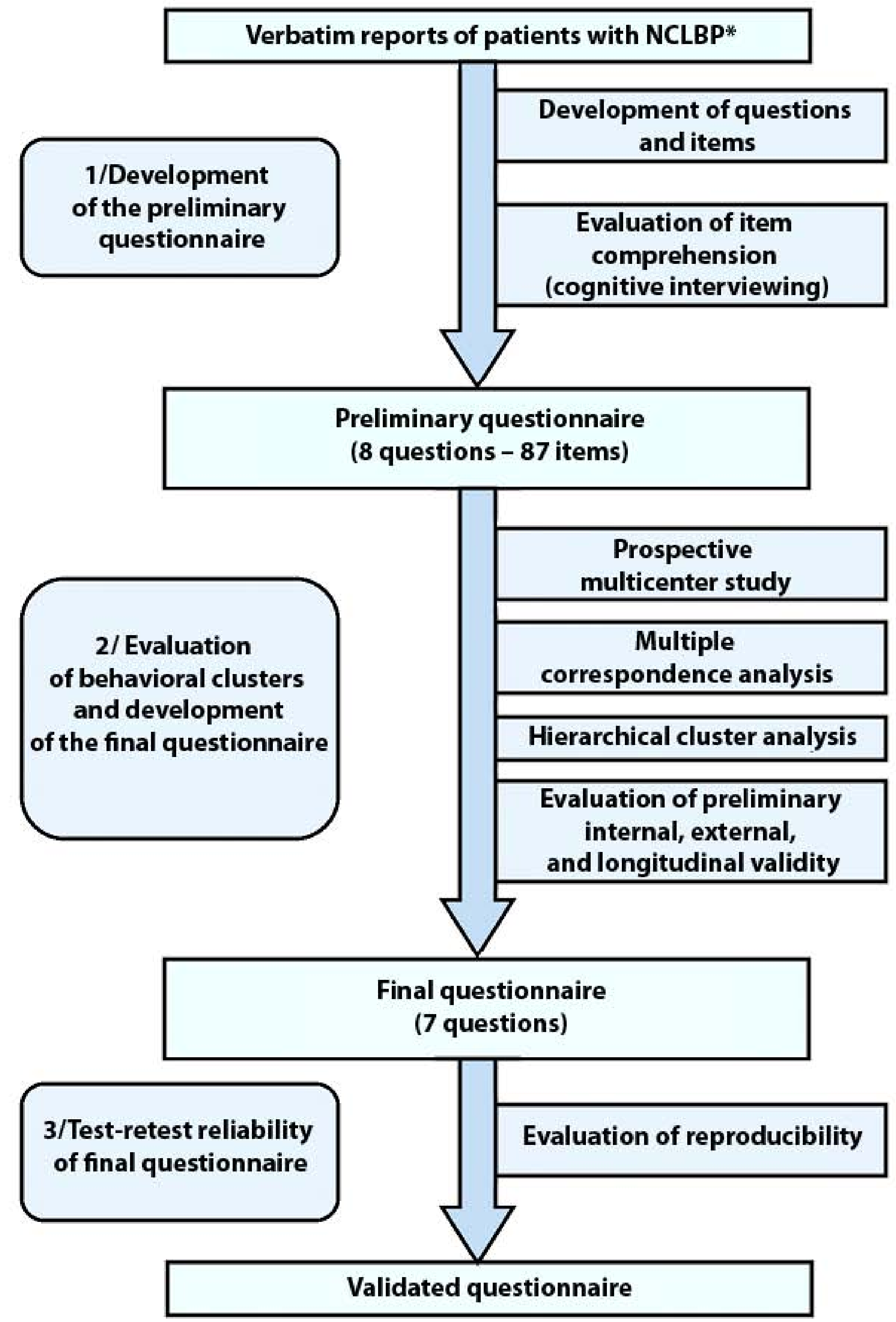


This questionnaire helps to understand how you manage low back pain. For each question, please choose the sentence that best describes you now.

\section{Question 1 - My low back pain}

$\square$ I feel the pain is dragging me down.

$\triangle$ I manage with the pain.

I am afraid the pain will never stop.

\section{Question 2 - My usual activities}

$\triangle$ I have learned to deal with the pain while going about my usual activities.

$\square$ I no longer carry out my usual activities.

I have had to stop some of my usual activities.

\section{Question 3 - My emotions and mood}

$\square$ Emotionally, I feel trapped in a vicious circle.

$\bigcirc$ Emotionally, I can't handle the situation.

$\triangle$ It isn't always easy to handle the pain emotionally but I manage.

\section{Question 4- My physical activities during recreation and sports}

$\square$ I'm not physically active any more, because of my back.

$\triangle$ I have learned to continue being physically active, despite the back pain.

$\mathrm{O}$ am afraid to move during my physical activities.

\section{Question 5 - The future and the back pain}

$\triangle$ I accept the future, although I know the pain may still be there.

I am fearful about the future.

$\square$ I have trouble contemplating the future.

\section{Question 6 - The reactions of others to back pain}

$\square$ I feel I'm a burden for others.

$\triangle$ I feel supported by others.

$O$ I feel that others minimize my back pain.

\section{Question 7 - Work}

$\triangle$ I have learned to do my work despite the back pain.

$\square$ I have stopped working, because of the back pain.

I still work, but I'm afraid the work will worsen the pain.

\section{Number of $\triangle$ :}

Number of $\square$ :

Number of $\bigcirc$ :

If the number is the same for two symbols, please choose the question that is most important to you:

Question number : 